DOI:

\title{
Türkiye'de Mobilya Sektörünün Durumu ve 2000'li Yıllardan Sonra Küreselleşme Etkisi ile Değişimi
}

\section{Zeynep TERECE ${ }^{1}$, Jülide EDİRNE ERDİNÇ ${ }^{2}$, Füsun SEÇER KARİPTAŞ ${ }^{3}$}

\author{
1,2T.C. Haliç Üniversitesi, Mimarlık Fakültesi / Mimarlık Bölümü, İstanbul, \\ Türkiye \\ ${ }^{3}$ T.C. Haliç Üniversitesi, Mimarlık Fakültesi / İç Mimarlık Bölümü, İstanbul, \\ Türkiye \\ ${ }^{1}$ ORCID: 0000-0002-7522-8697 \\ 2ORCID: 0000-0002-1367-7550 \\ ${ }^{3}$ ORCID: 0000-0003-1594-6061
}

*Sorumlu Yazar e mail: julideedirne@halic.edu.tr

Geliş Tarihi: 31.01 .2020

Kabul Tarihi: 18.03 .2020

Atıf/Citation: Terece, Z., Edirne Erdinç, J. ve Seçer Kariptaş, F. “Türkiye’de Mobilya Sektörünün Durumu ve 2000'li Yıllardan Sonra Küreselleşme Etkisi ile Değişimi” Haliç Üniversitesi Fen Bilimleri Dergisi 2020, 3/1: 159-180.

\section{Araştırma Makalesi/ Research Article}

\section{Özet}

Küreselleşme ile birlikte teknolojinin tüm dünyadaki etkisi Türkiye'de de yaygın olarak hissedilmiştir. Bu süreç dünyadaki ve Türkiye'deki mobilya tasarımlarında köklü değişimler yaratmıştır. Türkiye'de mobilyanın yaygınlaştı̆̆ı Cumhuriyetin kuruluşu sonrasındaki dönemde malzeme çeşitliliğindeki azlık ve teknik yetersizliklerden dolayı özgün bir tarz oluşmamıştır. Bunun sonucunda mobilya üretim tekniği kısıtlanmış ve diğer ülkeler tasarım açısından taklit edilmiştir. Cumhuriyetin kuruluşu sonrası devletin oluşturduğu standartlar nedeniyle mobilya sektöründe kullanılan malzemeler yurtdışından getirilmiştir. Apartman dairelerine geçişler modern konut kavramını oluştururken mobilya talebini de artırmıştır. Bunun sonucunda Cumhuriyet Dönemi'nde mobilya sektörü, sosyal değişim ve teknolojik gelişmeleri takip ederek kendini yenilemeye başlamıştır. Batı mobilya ürünlerine yönelimin artması ve bu ürünlerin örnek alınması aynı zamanda özgün tasarımların oluşmasına katkıda bulunmuştur. Türkiye'de 1970'li yıllarda modern tarzda endüstriyel üretim başlamıştır. 2000'li yıllara gelindiğinde ise orta ve büyük ölçekli işletmelerin sayısı giderek artmış ve dünya ölçeğinde mobilya ihracat ve ithalatında sahip olduğu pay 
büyümüştür. Çalışmada, Türkiye'de mobilya tasarım ve mobilya üretiminin sahip olduğu özelliklerinin daha doğru analiz edilmesi açısından mobilya sektörünün gelişim süreci tüm yönleriyle ele alınmıştır. Bu doğrultuda mobilya tasarım sürecini etkileyen tasarım kriterleri tespit edilerek, mobilya tasarımının mevcut durumu sektörün dünya pazarındaki yerine yönelik veriler kullanılarak aktarılmaya çalışılmıştır.

Anahtar Kelimeler: Mobilya tasarımı, Mobilya sektörü, Modern mobilya, Küreselleşme.

\title{
The Status of Furniture Sector in Turkey and Its Change After 2000s by the Effect of Globalization
}

\begin{abstract}
With the globalization, the effect of technologyhas been felt worldwide including Turkey. This period has created radical changes in furniture design throughout the world and in Turkey. The proliferation of furniture in post-republic era, an original style in the furniture production has not been developed in Turkey because of the material shortage and technical deficiency. As a result of this, the technique of furniture production has been limited and other countries have been followed after due to their furniture design. After the proclamation of the republic, as the state authorities have regulated the standards, the materials for furniture production have been mainly imported from foreign countries. While the move into flats has accelerated the modern housing concept, it has also increased the demand for furniture.As a result of that, the furniture sector has started to renew itself by following social changes and technological developments during the republican period the furniture. The increase in preference for Western-style furniture and their being seen as exemplary have also contributed to the formation of authentic designs. In 1970s, modern industrial production has begun in Turkey. In 2000s, the number of small and bigbusinesses has increased and the part they have taken in the furniture exportation and importation in the world has gotten bigger. In this study, the progress of furniture sector has been tackled in all its parts for a better analysis of the features of furniture design and production in Turkey.. In line with this, having determined the design elements which influence the process of furniture design, the current situation of furniture design has been expressed by using the data for the place of the sector in the global market.
\end{abstract}

Keywords: Furniture design, Furniture sector, Contemporary furniture, Globalization. 


\section{Giriş}

İnsanoğlu varoluşundan bu yana çeşitli ihtiyaçları için mobilya tasarlamış ve üretmiştir. Mobilya, insanların yaşamlarını kolaylaştırmak ve rahat bir yaşam sürmelerini sağlamak için hep gerekli olmuştur. Mobilya geçmişten günümüze insan yaşamı için vazgeçilmez bir araç olarak karşımıza çıkmaktadır. İnsan yaşamına mobilya kavramı ilk olarak taş ve kum malzemelerinin kullanılması, taşların yontularak oturaklar, ağaç yaprakları veya hayvan derileri kullanılarak yataklar üretilmesi şeklinde girmiştir. Geçmişten günümüze toplumların çok çeşitli ekonomik düzey ve kültürel yaşamları sonucu farklı mobilya kullanımları görülmektedir. Mobilyalar zamanın ve mekânın teknolojik gelişmeleriyle beslenerek geleneksellikten çıkıp modern formuyla günümüze ulaşmıştır. İnsan yaşamında ihtiyaçların çoğalması, teknolojinin hızla büyümesi mobilya çeşitlerinin de artmasını da sağlamıştır. Mobilya seçimlerinde eğitim, kültür, ekonomik ve sosyal alışkanlıklar arasındaki farklılıklar etkili olmaya başlamıştır.

Türkiye'nin çağdaş dünyaya açılımıyla başlayan değişimler, mobilya sektöründe de kendini hissettirmiştir. Konut talebinin artması, mekân tiplerine uygun, bireylerin zevk ve ihtiyaçlarına göre mobilya üretiminin artmasına neden olmuştur. Değişen dünya koşulları, yeni ürünlerin sosyal yaşama dâhil olması tüketicilerin bilinçlenmesi mobilya sektörünün gelişimine büyük oranda yansımıştır. Bu kapsamda çalışmada, tasarımlara ve tasarımcılara etki eden sektörün bulunduğu durumun irdelenmesi amaçlanmıştır.

\section{Materyal ve Metot}

Çalışmada Türkiye'de mobilya tasarımı ve mobilya sektörünün gelişim süreci içinde taklit edilen ürünlerin yeri araştırılmıştır. Çalışma süresince konu ile ilgili literatür taraması yapılmıştır. Bu alanda yayınlanan tez, dergi, kitap, gazete ve makale çalışmaları incelenmiştir. Mobilya sektörünün Türkiye'de ve dünyadaki durumunu ortaya koymak 
adına konu ile ilgili hazırlanan raporlardan yararlanılmıştır. Eldeki veriler 1şığında mobilya sektörünün Türkiye ölçeğindeki yeri ve gelişim süreci bir araştırma değerlendirmesi olarak ortaya konmuştur.

\section{Mobilya Kavramı}

Mobilya, insan anatomik yapısının gereği olarak girdiği çeşitli biçimlere hizmet amacıyla insan ölçüsüne uygun olarak tasarlanmış farklı fonksiyonları karşılayan nesnedir [1]. Mobilya, yaşam şartlarını kolaylaştıran, mekâna düzen vermeyi sağlayan ve bulunduğu çevreyi kullanışlı hale getiren nesnelerin tümüne verilen addır. Dolayısıyla bir mekânı tamamlayan önemli olgulardan biridir. "Mobilya oturulan yerlerin süslenmesi ve her türlü kullanım amaçları için donatılmasına yarayan yeri değiştirilebilen eşya olarak tanımlanmaktadır" [2].

Toplumların yerleşik düzene geçmesi ile birlikte insanlar dört yanı çevrili bir üst örtü altında yaşamaya başlamıştır. Temel barınma ihtiyacının karşılanmasının yanı sıra, yaşam mekânlarını daha rahat ve kullanışı bir hale getirmek arzusundan doğan ikincil ihtiyaçların meydana çıkması sonucu farklı alet ve eşyalara duyulan ihtiyaçlar mobilya kavramının farklı biçimlerde şekillenmesini sağlamıştır. İhtiyaçlarla beraber artan gereksinimler mobilyaya yönelik beklentileri de artırmıştır. Mekânların yapılış amaçlarına uygunluğu önemli olmakla beraber, kullanıcıya da gerekli olan konforu sağlaması ön plana çıkmıştır. $\mathrm{Bu}$ bağlamda gereksinimlerin çoğalması ve yapım, alet ve makinelerin icadıyla seri üretim mobilya tarzları geliştirilmiştir.

Temel ihtiyaçlardaki değişimin getirdiği farklılıkların yanı sıra tasarımda dönemin kültür yapısı, estetik anlayışı ve o dönemin alışkanlıkları da mobilyaya yansıtılmıştır. Mobilyalar sadece duyulan gereksinimin giderilmesi amaçlı tasarlanmamış, zamanla tasarım ve sanatta etkili olan akımlar mobilyanın da farklılaşmasına sebep olmuştur. Mobilya, sadece beklenen işlevin karşılanması için değil, sosyal ve ekonomik semboller ve sosyolojik mesajlar için de kullanılmıştır. Tarih öncesi devirlerde, zenginlik ve sosyal statü sembolü olarak görülen 
mobilyaların daha sonra ortaya çıkan çeşitli sanat akımları ile sadeleştiği ve fonksiyonelliği ön planda tutulduğu görülmektedir. Endüstri devrimi ile seri üretim kavramı doğmuş, bu kavram mobilya tasarımını ve üretimini değiştirmiştir. Modernizm, tasarımda 20.yüzyılda yeni estetik anlayışların ortaya konduğu bir dönem olmuştur. Bauhaus gibi akımlarla mobilya tasarımı bir eğitim konusu ve manifesto haline gelmiştir. Mobilya üretiminde rekabet ortamı artmış, teknolojinin gelişmesiyle ucuz malzemeler üretilmiş ve işçilik kolaylaşmıştır [1].

Mobilya tasarımındaki bu tarihsel değişim tasarım ve teknolojideki değișimlerin değerlendirilmesine yardımcı olmaktadır. Tarihsel değişimlerin irdelenmesi mobilya sektörünün gelişiminde önemli ipuçlarının elde edilmesini sağlayacaktır.

\subsection{Günümüzde mobilya tasarım sürecini etkileyen tasarım kriterleri}

Modern mobilyada en önem verilen hususlar, malzeme kullanımı, hafiflik, hijyen, malzemede sağlamlık, sürdürülebilirlik, strüktür, ergonomi, ölçü, deteylarda basitliktir. Çağımızın değişmesi yeni malzemelerin mobilya tasarımında kullanılmasını gerektirmiştir. Teknolojinin her geçen gün gelişmesi ile birlikte mobilya tasarımında yararlanılabilecek olanaklar da artmıştır. Cam, çelik, aluminyum ve tekstil günümüzde endüstriyel mobilya tasarımında yaygın olmakla birlikte plastik malzemelerin kullanımı da yaygınlaşmıştır. Hafiflik, modern mobilya tasarımında 20. yüzyılın başından bu yana endüstride ele alınan önemli bir kriterdir. Mobilyadaki hafiflik arayışı açısından malzeme kullanım yöntemleri 21. yüzyılın başından itibaren oldukça gelişmiştir. Teknolojinin ilerlemesi, daha hafif malzemelerin geliştirilmesini sağlamıştır. Hafif mobilya üretimi nakliyede ve kullanımda kolaylık, hız ve verim sağladığı için günümüzde tercih edilmektedir. 20. yüzyılda olduğu kadar çağımızda da hijyen modern mobilya tasarımında aranan özellikler arasındadır. Mobilyanın toza ve kire karşı dayanımı geliştirilen teknoloji ile artırılmaktadır. Kullanılacak tekstil 
ürünlerinin rahat temizlenebilir olması bu ürünlerin kullanıcılar tarafindan tercih edilme sebepleri arasında yer almaktadır. Malzeme kullanımında sağlamlık kullanıcıya güven verebilecek şekilde ele alınmaktadır. 20. yüzyılda başlayan sanayileşmenin getirdiği kirlenmeyi ve doğal kaynakların tükenmesini önlemek amacıyla endüstriyel kirlilik oluşturan ve işlenmesi için fazla enerji gerektiren malzemeler yerine geri dönüştürülebilir ve sürdürülebilir malzemelere yönelim başlamıştır. Tasarımcılar, mobilya sektöründe de geri dönüştürülebilir malzemelerin mukavim kullanımlarını sağlayacak şekilde yeni ürünler geliştirmektedir.

Teknoloji, malzeme, üretim ve dönüşüm uygulamaları günümüzde modern mobilyalarda çeşitli form ve dayanımda pekçok strüktürün gelişmesini sağlamıştır. Kaliteli tasarım anlayışı, günümüz mobilyalarında aranılan bir kriterdir. Yapay strüktürler kullanmaksızın strüktürün ve detayların görünür kılınması, mobilyanın ortaya çıkmasını sağladığı gibi bakım ve üretim kolaylığı da sağlamaktadır. Sade tasarım, üretimde verimlilik ve sağlamlık ilkeleriyle modern tasarım oluşmaktadır.

Ekonomik ve mütevazi tasarım anlayışı, mobilyanın geniş kitlelere ulaşabilmesi amacı ile doğmuştur. Günümüzde sosyal değerlere olan duyarlılık ticari kaygılarla azalsa da endüstriyel verimlilik için ekonomik tasarımlar üretilmektedir. İşlevsellik, denge, hafiflik, kolay taşınabilirlik, bakım kolaylığı, uzun ömürlü olma, hareketlilik, kolay sökülüp monte edilebilirlik, ergonomi, kullanımda esneklik gibi kriterler modern mobilya tasarımının olmazsa olmaz özellikleridir. Günümüzde de mobilya tasarım sürecine bu özellikler dikkate alınarak yön verilmektedir.

\section{Türkiye'de Mobilya Tasarımı ve Üretim Sektörüne Etkisi}

Türkiye'de Cumhuriyet Dönemi sonrası mobilya sektöründe, hızla ilerleyen teknolojik gelişmeler doğrultusunda tasarım, üretim, tüketim süreçleri birbirini takip ederek büyümüştür. Böylece Türkiye'de 
küreselleşme süreciyle birlikte önem kazanan mobilya tasarımı, birçok mobilya firmasının sektöre girmesini sağlamıştır. Teknolojik yeniliklerin ülkemize girmesi, dışa açılma durumu, batılı yaşam tarzının benimsenmesi ve dış ticaretin artması, mobilya firmaları arasında rekabeti sağlamıştır. Bu rekabet duygusu sektörde özgün tasarım olgusunu oluşturmuştur. Marka olma isteği girişimcilerin sektör tarafından algılanmasını ve önemsenmesini sağlamıştır.

Türk mobilya sektöründe tasarımın önemi sektördeki imalatçılar tarafindan tam olarak anlaşılabilmiş değildir. Birçok firma, yabancı firmaların ürünlerini taklit ederek, kendi bünyelerinde tasarımcı bulundurmadan üretim yapmaya çalışmaktadır. Çoğu firma aynı yolu izlediği için piyasada, birbirine benzeyen çok fazla modelle karşılaşılmaktadır. Bu da kullanıcılarda farklı ve özgün ürün görme isteği oluşturmuştur. Bunun üzerine son yıllarda firmalar, üretim süreçlerinde tasarımcı bulundurma ihtiyacı duymuştur.

Mobilyada trendler, fonksiyonellik ve estetik bakış açısına paralel olarak önemli bir değişim yaşanmaktadır. Bu değişime bakıldığında mobilya sektörünün çağdaş dünyadaki üreticilerle rekabet edecek düzeyde sürekli gelişim göstermesi kaçınılmaz hale gelmiştir. Ev mobilyalarının yanı sıra ofis ve bahçe mobilyaları da bu değişime ayak uydurmaktadır. Yıllarca Batı mobilyasını örnek alarak ilerleyen tasarımcıların ufku açılmış ve tasarımcılar mobilyaya farklı bir bakış açısıyla yaklaşmaya başlamışlardır. Örnek alınan çalışmalar Türkiye'nin kültürüne, ekonomik koşullarına, coğrafi konumuna göre şekillendirilerek yeni tasarımlar oluşturulmaktadır. Her eski ürün yeni yapılan diğer ürünün üzerine yeni fonksiyonlar ekleyerek başka türlerde karşımıza çıkmaktadır. Bu da günümüz tasarımcılarının özgün tasarım yapmasının önünü açmıştır. Özgün tasarım ve markalaşma son dönemlerde mobilya sektörünü ilgilendiren önemli kavramlar olmuştur. Tasarımcıların tasarımlarında kimlik oluşturmasını, dış piyasada isim yapmasını, çok önemli fuar ve sergilerde yer almasını ve Türkiye'nin ürünlerinin ön plana çıkmasını sağlamıştır. 


\section{Türkiye'de Mobilya Sektörü ve 2000'li Yıllardan Sonra Küreselleşme Etkisi ile Değişimi}

Türkiye'de mobilya sektörü diğer sektörlere göre daha hızlı ilerleyen en eski imalat sektörlerinden biridir. Ülkemizde 1970'li yıllar öncesinde küçük yerlerde varlığını devam ettiren mobilya sektörü, belirli bir süre sınırlı üretim yapmak durumunda kalmıştır. Mobilya atölyelerinin birbirinden habersiz ve küçük olması aralarındaki ilişkiyi kısıtlamıştır. Bu durum da teknolojik gelişmeleri yavaşlatmış ve el emeğinin yoğun olarak yer aldığı bir sektör olmasına neden olmuştur. İhtiyaç için üretilen küçük ev eşyaları ve iç piyasada bulunan mobilyalar sektörün büyük çoğunluğunu oluşturmuştur. Dolayısıyla da Türk mobilya endüstrisi, çoğunluğun geleneksel yöntemlerle çalıştığ1 atölye tipi ve küçük ölçekli işletmelerin ağırlıkta olduğu bir konumda kalmıştır.

2000'li yılların başından itibaren, orta ve büyük ölçekli işletmelerin sayısı giderek artmaya başlamıştır. "Türkiye'de mobilya sektörü, pazarın yoğunlaştı̆̆1 ve orman ürünlerinin yoğun olduğu belirli bölgelerde toplanmıştır. 2014 yılı SGK verilerine göre mobilya sektörü imalat sanayi içinde 20.867 işletme ile dördüncü, yarattığ1 165.118 kişilik istihdam ile yedinci sırada yer almaktadır. Mobilya sektörünün Türkiye'de yoğunlaştığı iller incelendiğinde; en fazla Kayseri, Bursa, Ankara, İstanbul ve İzmir'de mobilya üretiminin yapıldı̆̆ 1 dikkat çekmektedir. Bunun dışında Eskişehir, Sakarya, Bolu, Trabzon, Zonguldak, Balıkesir, Antalya ve Burdur'da da mobilya üretimi yapılmaktadır" [3]. Mobilya sektöründe faaliyet gösteren işletmeler çoğunlukla pazara yakın ve hammaddenin kolay temin edildiği bölgelere yerleşmişlerdir. Büyük ormanlık alanlara sahip olan, bunun sonucu olarak da ağaç sanayisinin hızlı bir şekilde geliştiği Bursa (İnegöl) bölgesi de yüksek bir gelişim göstermiştir. Hammadde kaynaklarına yakın olmasının avantajını iyi değerlendirmiştir. Bölgenin ihracatta yakaladığı başarı, Bursa, İnegöl'ün mobilyada önemli bir uluslararası merkez olma yolunda olduğunu göstermektedir. 
“İstanbul' da mobilya sektörü muhtelif yerlere dağılmış olmakla beraber, en önemli iki merkez İkitelli Organize Sanayi Bölgesi’ndeki Masko (778 mağaza) ve küçük sanayi sitesindeki Modoko (350 mağaza)'dur. Ankara mobilya üretiminde her zaman için önemli bir merkez olmuştur. Ankara'da mobilya sektörü Siteler semtiyle özdeşleşmiştir. Siteler 1960'lı yıllarda Marangozlar Odası'nın önderliğinde kurulmuş olup, bugün 5.000 dönüm arazi üzerinde faaliyet gösteren büyük bir organize sanayi bölgesidir. Bölge küçük ve orta ölçekli mobilya üretimi yapan birçok işletmeyi barındırmaktadır. Sitelerdeki kayıtlı firma sayısının 10.000'i aştığı sanılmaktadır" [3].

Kanepe, koltuk ve yatak üretimiyle başlayan Kayseri, mobilya sektöründe teknolojik gelişmeler ve yeni yatırımlar sonucunda bugün mobilyanın her dalında üretim yapan firmaları içinde bulundurarak Türkiye'nin önemli mobilya merkezi haline gelmiştir. Kayseri daha çok ev mobilyası ihracatı yapmaktadır.

İzmir bölgesi istihdam düzeyine göre Kayseri'nin ardından 5. s1rada gelmektedir. İzmir'de, Karabağlar ve Kısıkköy sektörün yoğunlaştığı bölgelerdir. Sahip olduğu liman ve ulaşım kolaylığ1 sayesinde sektör ihracatta önemli atılımlar içerisindedir. Firma başına düşen ça1şan sayısı açısından Türkiye ortalamasının altında istihdam düzeyine sahip olan İzmir bölgesinde daha çok küçük firmalar bulunmaktadır.

Kentsel dönüşümün hız kazandığı yıllar itibariyle, mobilya üretimi büyük ölçüde yeni konut inşaatlarına ve gelir artışına paralel bir seyir izlemektedir. Ofis mobilyaları gibi daha özellikli konulardaki mobilya üretimi, bu nedenle talep esnekliği yüksek bir tüketim malı olması nedeniyle talep ve kapasite kullanım oranları ekonomik dalgalanmalara paralel olarak inişli çıkışlı olmaktadır. İç pazardaki talep daralması kapasite kullanımının artırılamaması yanı sıra dış talep yetersizliğinin de getirdiği finansman, çalışanlarla ilgili sorunlar, yerli ve ithal hammadde yetersizliği gibi üretimin ve sektörün yaşadığı başlıca sorunlara neden olmaktadır (TC Ticaret Bakanlığı). 


\subsection{Türkiye'nin dünya mobilya ihracatındaki yeri}

Mobilya sektörü dünyada rekabetin yoğun yaşandığı, bu rekabetin Türkiye ekonomisine de istihdam ve ticaret hacmi yönünden önemli katkılar veren bir sektördür. Genel dünya ihracatı ve dünya mobilya sektörü ihracat rakamları incelendiğinde, 2001-2010-2016-2017 y11ları itibariyle dünya mobilya sektörünün genel dünya ihracatı içindeki pay1 2001 yılında \% 1,01, 2010 y1lında \% 0,88, 2016 y1lında \% 1,08 seviyelerinde olduğu görülmektedir. Dünya mobilya sektörü, 2016 y1linda ihracat rakamı 171,2 milyar, 2017'de ise 181,5 milyar dolar olarak gerçekleştirirken, 2030 yıllarında mobilya sektörünün ticaret hacminin 1 trilyon doları geçeceği tahmin edilmektedir [4].

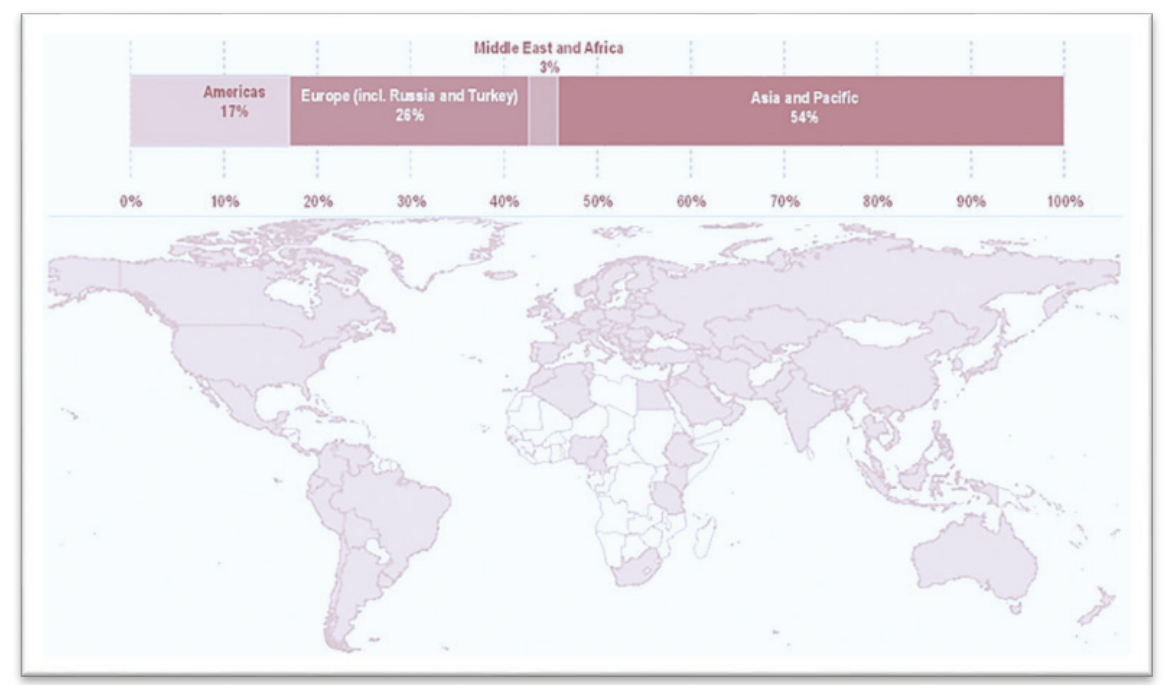

Şekil 1. Dünya mobilya üretiminin bölgelere göre yüzde dağılım1 [5]

Çin, dünyada mobilya üretiminin \% 39'unu gerçekleştirerek lider konumdadır. Diğer büyük mobilya üretim ülkeleri Amerika Birleşik Devletleri, Almanya, İtalya, Hindistan, Polonya ve Vietnam'dır. 2009'dan 2018'e kadar Asya ve Pasifik ülkeleri de mobilya üretimini iki kattan fazla artırmıştır. 2018'de dünya mobilya üretiminin yarısından fazlası Asya ve Pasifik’te gerçekleşmiştir. 
Dünya mobilya ihracatında ise $\mathrm{AB}$ ülkelerinin büyük ölçüde söz sahibi olduğu görülmektedir. Birçok $A B$ ülkesinde mobilya imalatı temel bir endüstridir ve dünyada rekabeti kontrol eden bir konuma sahiptir. Almanya ve İtalya Birliğin en büyük üretici ve ihracatçılarıdır. Ardından Polonya, Fransa, Danimarka, Belçika, İsveç, Danimarka, Avusturya, İngiltere ve Hollanda diğer önemli mobilya ihracatçısı ülkeler olarak karşımıza çıkmaktadırlar.

200

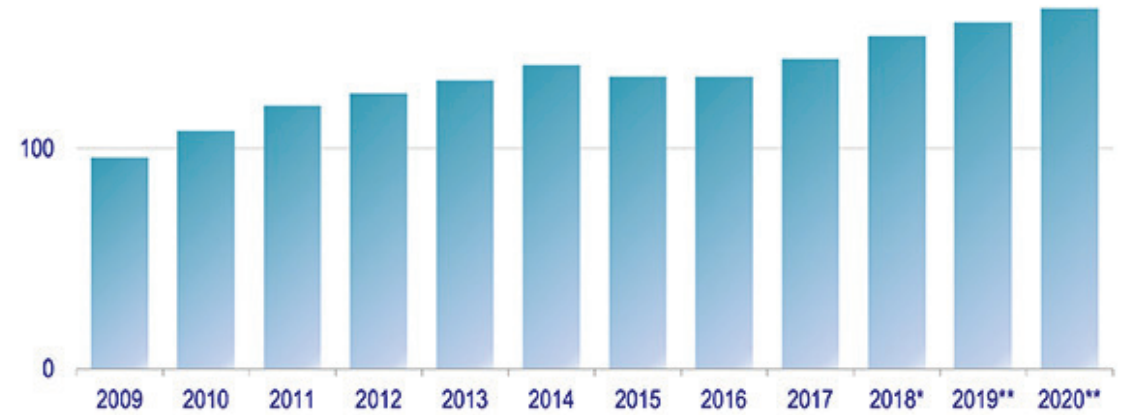

Şekil 2. Dünya mobilya ticareti 2009-2020 Mevcut milyar ABD doları [5]

Mobilya üretim ve ticaretini elinde bulunduran yaklaşık 100 ülkeden oluşan grubun uluslararası mobilya ticareti 2018 y1lında yaklaşık 150 milyar dolar olarak gerçekleşmiştir. $\mathrm{Bu}$, dünya üretim ve ticaretinin yaklaşık \%1'ine karşılık gelmektedir. 2019'da başlayan büyümenin 2020 'de de devam edeceği, artan ticaret gereksinimleri ve korumacı politikalardan kaynaklanan önemli farklılaşmalar olacağ 1 öngörülmektedir. CSIL'nin “Worldfurniture Outlook 2019” raporuna göre, mobilya tüketiminin dünya genelinde artması ile en hızlı büyüyen bölge Asya ve Pasifik olmaya devam edeceği, diğer tüm bölgeler için büyüme hızının reel olarak \% 1 ile \% 3 arasında olacağ mektedir [5]. 
Dünya Mobilya İhracat (Milyar \$)

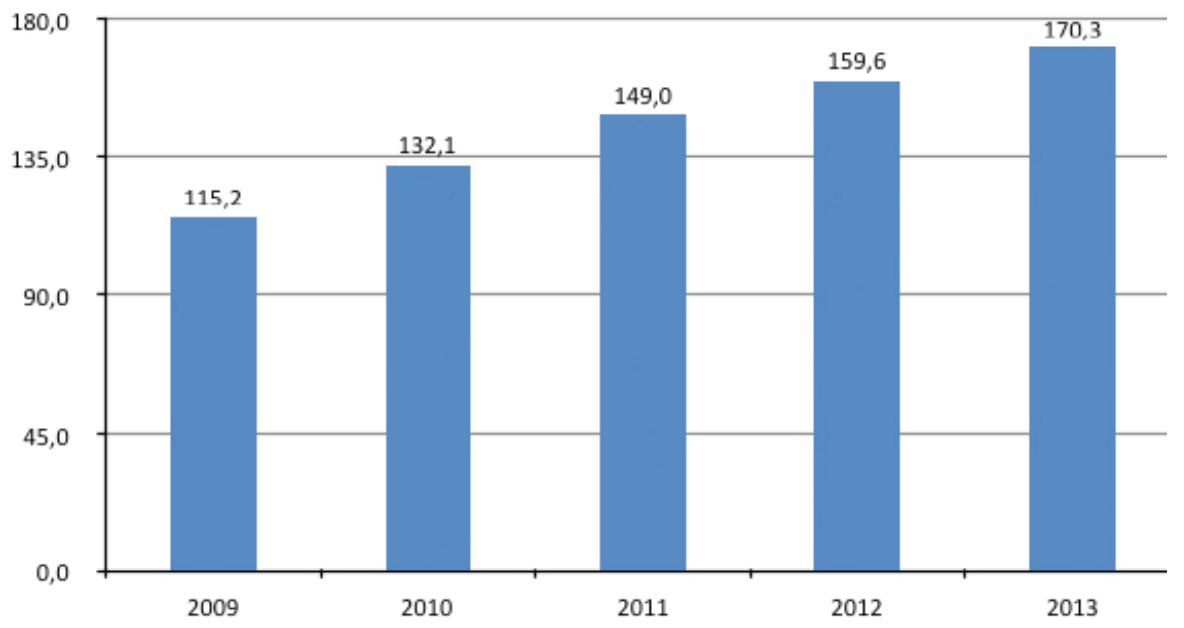

Şekil 3. Dünya Mobilya İhracatı (Milyar \$) [6]

Dünya mobilya ihracatı Orta Anadolu İhracatçı Birlikleri Mobilya Sektör Raporu'na göre, 2009 senesinde 115,2 milyar \$ seviyesindeyken 2013 senesine gelindiğinde bu durum 170,3 milyar \$ seviyesine yükselmiştir (Şekil 1) [6] [7] [8]. Dünya mobilya ihracatında en büyük pay Çin'e ait olmakla mobilya ihracatında 54 milyar dolarlık hacmiyle dünya mobilya pazarında ilk sırada yer alan Çin'in ardından Irak, Almanya, Suudi Arabistan, Libya, Amerika Birleşik Devletleri ve Fransa lider pazarlar durumundadır.

Mobilya dış ticaretinde son yıllarda göze çarpan başlıca gelişim mobilya pazarının dışa açılma oranındaki artıştır. 47 milyar dolara yaklaşan mobilya dış ticaret açığı ile ABD, 70 milyar doları aşan ihracatı ile $A B$ ve yaklaşık 56 milyar doları aşan mobilya dış ticaret fazlası ile Çin sektörün önemli aktörleri olarak dünya mobilya piyasalarını yönlendirmektedirler. Global Market Insights'ın yaptığı araştırmaya göre, mobilya pazarındaki gelişimin neticesinde, Avrupa mobilya pazarının 2024 yılına kadar 178 milyar € 'ya ulaşması öngörülürken, Almanya, İtalya, Polonya ve Fransa'nın yanı sıra, bölge dışındaki üreticilerin son on yılda üretim kapasitelerini geliştirmeleri bu öngörüde rol oynamaktadir. 
Konut mobilyası pazarının, sosyoekonomik kalkınma ve hükümetler tarafından konut sübvansiyonlarının yanı sıra artan bir nüfusa uyum sağlama ihtiyacı nedeniyle 2024'e kadar \% 5'in üzerinde büyüme kaydetmesi aynı raporda belirtilmiştir.

2017 yılında ahşap mobilya dünya pazarında \% 60'lık pazar payı ile hakim olmuştur. Yüksek dayanıklılık ve mukavemet ile birlikte düşük fiyat seçeneği önümüzdeki birkaç yıl içinde ahşap malzeme talebini artıracaktır. Yeşil binalarda doğal ürünlerin tercih edilmesi, ahşap mobilyada ürün satışlarını olumlu etkilediği görülmektedir.

Türkiye'nin dünya mobilya ihracatındaki 2016 yılı itibariyle pay1 ise \% 1,1'dir. İstanbul Mobilya Kâğıt ve Orman Ürünleri İhracatçıları Birliğinin 2020 Ocak-Şubat dönemi ihracat verilerine göre, 2020'nin ilk ayında geçen yılın aynı dönemine göre yüzde 15 artış ile mobilya ihracatı 578 milyon dolardır. Bu rakamlara göre Türkiye mobilya üretiminde 13.sırada yer almaktadır ve üretiminin yüzde 36'sını ihraç etmektedir. Bu rakamlar 179 ülkede Türk üretimi mobilya kullanılmasını sağlamaktadır [9].

2018 yılında 2.7 milyar dolara yakın mobilya ihracatını ağırlıklı olarak, Irak, Almanya ve Suudi Arabistan ülkelerine gerçekleştirmiştir. $\mathrm{Bu}$ ağırlığın coğrafi olarak yakın, ulaşım kolaylığına sahip ülkelerde olduğu görülmektedir [10].

Türkiye'nin mobilya ihracatı 2019 için 3.5 milyar dolar olarak gerçekleşmiş ve 2023 öngörüsü ile 10 milyar dolar ihracat ve 25 milyar dolar üretim hacmine ulaşma hedeflemektedir [10]. 


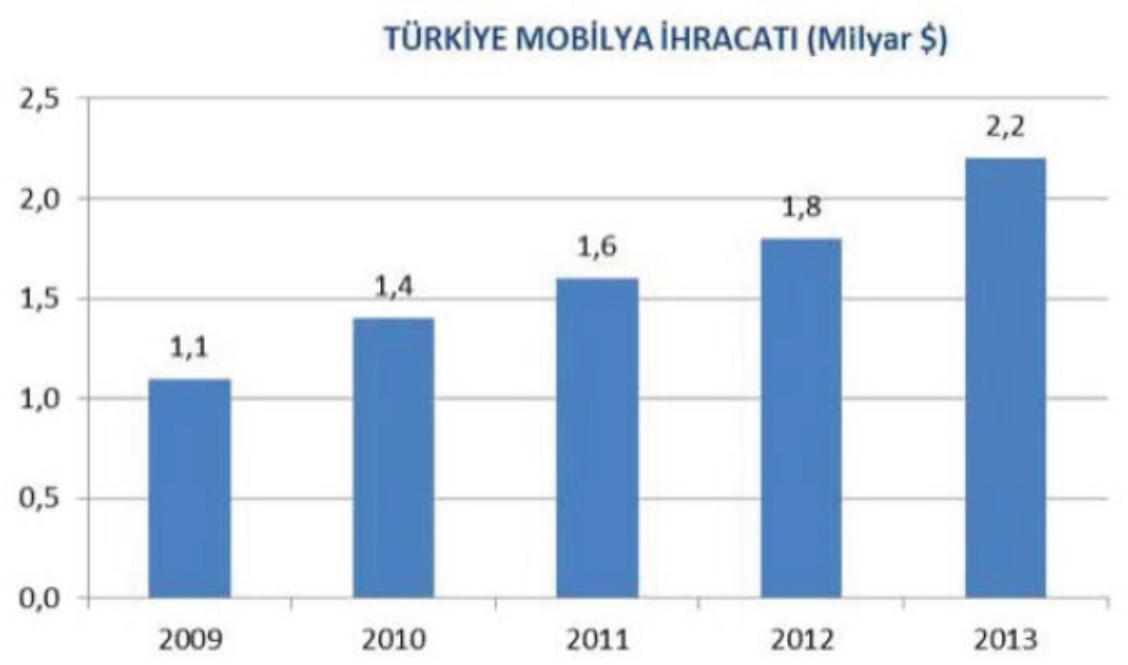

Şekil 4. Türkiye mobilya ihracatı 2009-2013 verilerine göre değişimi (Milyar \$) [6]

\subsection{Türkiye'nin dünya mobilya ithalatındaki yeri}

Dünyada mobilya ithalatı Orta Anadolu İhracatçı Birlikleri Mobilya Sektör Raporu'na göre, 2009 senesinde 116 milyar \$ seviyesindeyken, 2013 senesinde 161,2 milyar \$ seviyesine yükselmiştir. İthalat konusunda ABD birinci sırada yer alırken, Almanya ikinci, Fransa üçüncü sıradadır. Bunları İngiltere ve Japonya takip etmektedir. Kanada, Belçika, İsviçre ve Rusya da mobilya ithalatında önde gelen ülkeler arasinda yer almaktadır [7].

Türkiye mobilya sektörü 2016 yılında ihracat rakamı 2,2 milyar \$, ithalat rakamı 605,7 milyon \$’a varmıştır. Dünya mobilya ihracatı içinde Türkiye'nin 2016 yılındaki payı \% 1,30 dur. 


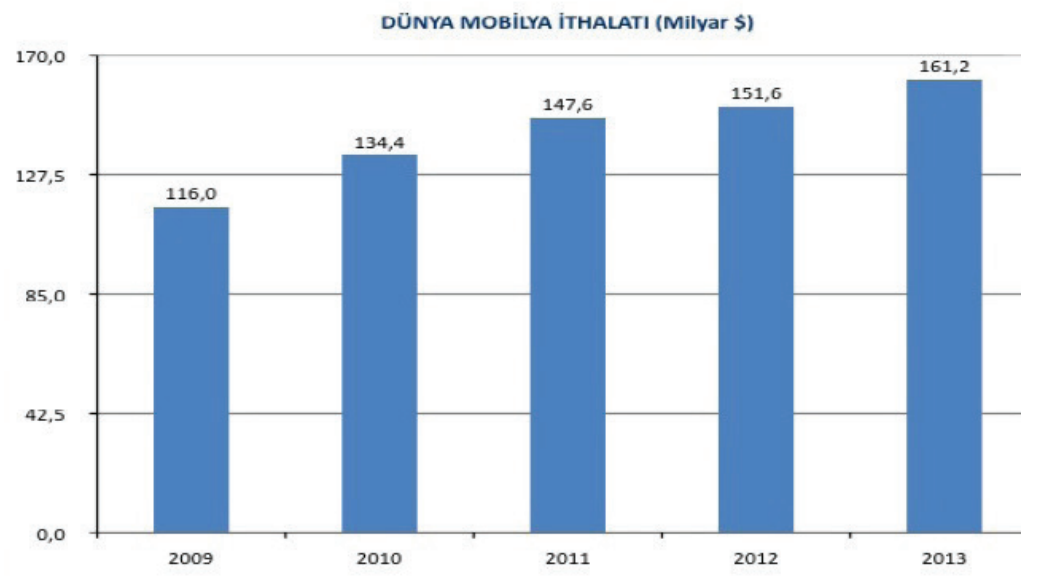

Şekil 5. Dünya Mobilya İthalatı 2009-2013 verilerine göre değişimi (Milyar \$) [6]

Türkiye mobilya sektöründe, ithalat düzeyi ihracat düzeyinden daha düşüktür [7]. 2009 senesinde 567,6 milyar \$ değerinde gerçekleşen ithalat durumu 2013 senesinde 968,6 milyar \$ değerine yükselmiştir (Şekil 5) [6].

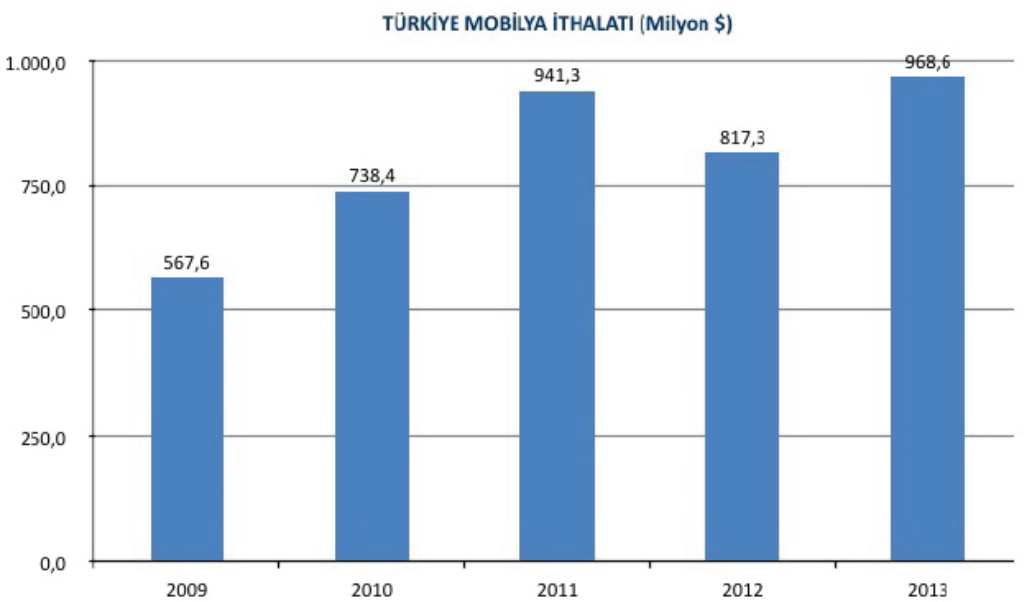

Şekil 6. Türkiye Mobilya İthalatı 2009-2013 verilerine göre değişimi (Milyar \$) [6] 
Türkiye'nin mobilya ithalat1 2018 yılında 592 milyon dolar düzeyinde gerçekleşmiştir. İthalat 2017 yılında bir önceki yıla göre artış gösterirken, 2018 yılında düşüşe geçtiği görülmektedir. TÜİK Dış Ticaret İstatistikleri Veri Tabanına göre 2017 de 947 milyon dolar olan ithalat, 2019 da 731 milyon dolara gerilemiştir [10].

Mobilya ithalatı 2018 itibariyle en fazla Çin, Almanya ve İtalya'dan gerçekleştirilmektedir. Son yıllarda Avrupa'nın mobilya üretiminde doğuya doğru bir yöneliş içerisinde olduğu bu durumu desteklediği, 2018 yılında 90 ülkeye mobilya ihracatı içinde en fazla ihracatı Birleşik Arap Emirlikleri, Irak ve Kazakistan’a yapmıştır. Özellikle Körfez Ülkeleri'nin Türk mobilya tasarımında yöneldiği lüks konseptine ilgi gösterdikleri belirlenmiştir.

Global ekonomik trendlerin mobilya taleplerini etkilemesi, nüfusun artışı gibi etkenler ithalatın yönünü etkilemektedir. Toplumun daha varlıklı hale gelmesiyle artan ve değişen talepler yanında çevresel bilinç artışı da mobilya üretimi ve kullanımını etkilemeye devam edecektir. Sürdürülebilir malzemelerin gerek mobilya gerekse paketleme malzemelerinde kullanılması, malzeme israfinı en aza indirme çabaları ve daha verimli lojistik, mobilya üretiminin karbon ayak izinin azaltılması gibi nitelikler mobilya ithalatında önemli konular haline gelecektir.

\section{Türkiye'de Mobilya Tasarım ve Üretiminin Sahip Olduğu Özellikler ve Sektörün Gelişimi}

Mobilya sektörünün Türkiye'deki başlangıcı çok eskilere dayanmış olsa da, modern tarzda endüstriyel üretim 70'li yıllarda başlamıştır. Globalleşme süreciyle kullanıcıların değişmesi ve gelişmesi, kalite anlayışı ve moda ürün taleplerini de beraberinde getirmiştir. Mobilya, günümüze gelinceye dek birçok süreçten geçmiştir. Farklı akımların, mobilyaların ve firmaların tasarım ve üretimleri ile yön belirleyerek ilerleme göstermiştir. 20. yüzyıl öncesi tarihi stillerin oluşturduğu mobilya tasarımlarına modern mobilya ters düşmüştür. Ancak modern 
tasarım mobilyada öz değerlerin ortaya çıkması ve işlevselliğin forma öncülük etmesi gerektiği savunulmuştur [11]. Bu sebeple, modern tasarım her çağda geçici olmadan, devamlı yenilenebilecek bir öze sahip olmuştur. Fiziksel, estetik, kullanım ve üretim özellikleri ile tüm zamanlarda, modern mimari yapılara uygun mekanlarda mobilya kullanılabilmektedir. Günümüzde modern tasarım, tasarımcıların farklı yorum ve uygulamaları ve farklı malzeme kullanımları ile hayat bulmaktadır. Bu açıdan modern mobilya tasarımı fiziksel, estetik, ergonomik, üretim, kullanım ve mekana uygunlukları göz önünde bulundurularak değerlendirilmekte ve bunlara göre tasarlanmaktadır.

İthalatın serbest bırakılmasından önce Türkiye'de tasarım kavramı oluşmamıştır. Büyük işletmeler yabancı tasarımcılarla, küçük işletmeler ise batı mobilyasını kendine model alarak üretimlerini sürdürmüşlerdir. Sektöre giren yabancı firmalar, Türk mobilya sektörüne kaliteli tasarım kavramını ve rekabetçi piyasa koşullarını getirmiştir. Rekabet oluşumu Türkiye sektörünü olumlu etkileyerek pazarlama olanaklarının artmasını sağlamıştır.

Yabancı firmaların alım gücü ve yabancı pazara ilgileri satıştan üretime göre Türk mobilya sektörüne yönelik girişimciliği artırmıştır. Mobilya sektöründeki firmaların tasarım ve tasarımcılara verdiği gecikmiş önem, Türkiye'de üretim kapasitesi ve buna bağl1 ekonomik değerin oluşmasını sağlamıştır. Türkiye'de mobilya sektöründe müşteri talebinin artması, sektörde teknik ve tasarım yönünden örnek al1nan batı mobilya ürünlerine yönelimi daha da çok artırarak zamanla özgün tasarımların oluşmasına katkıda bulunmuştur.

Teknolojik gelişmelere bağlı olarak iletişimin kolaylaşması ülkelerin birbirlerinden etkilenmesini sağlamıştır. Farklı ülkelerdeki çeşitli yaşam tarzları mobilyaların biçimini ve kullanımlarını etkileyerek pekçok mobilya çeşidinin doğmasını sağlamıştır. Türkiye'de tasarımcılar dünyadaki gelişmeleri takip ederek ve tasarlanan ürünleri inceleyerek, coğrafi konum ve bölgelere göre iklim koşullarını göz önünde bulundurarak, model olarak aldığı yabancı tasarım ürünlerine kendi yorum ve çizgisini katarak yol almıştır. Böylece ürünlere farklı işlev 
ve fonksiyonlar ekleyerek günümüz teknolojik malzemeleri ile ürün tasarlama noktasına gelmiştir.

20. yüzyılın başındaki modern hareketin yansımaları, mobilya tasarımında işlev ve form arasındaki ilişkinin temeli olarak 21. yüzyılın başında da etkisini korumuştur. Teknoloji, malzeme, üretim tekniği, tasarım yaklaşımı, ideoloji, yaşam şekli, sosyal değerlerdeki değişim ve dönüşümler günümüz mobilyasına çok fazla etki etmektedir. Modern mobilya tarzı, mekan içinde esnek kullanım özelliği ve ofis ve konut mobilyalarının farklı karakteristik özellikleri doğrultusunda şekillenmesiyle yaşam alanlarımızda özelleşmiştir. Buna karşılık, günümüzde yaşam mekanı ve çalışma mekanının iç içe olmaya başlaması mobilyaların farklı mekanlar için kullanılabilir olmasını gerektirmiştir. Modern mobilyanın rutin yaşam içerisinde hem ofis ortamında hem de konut mekanında çok amaçlı kullanımını sağlamıştır.

\section{Bulgular ve Tartışma}

Türkiye mobilya sektöründe ağırlıklı olarak yer alan küçük ve orta ölçekli işletmelerin çoğunluğu teknolojik düzey ve kalifiye teknik eleman yetersizliği sorunu yaşamaktadırlar. 'Mobilya ve Dekorasyon Eğitimi' veren okullarda teknoloji eğitiminin güncelleştirilerek kalitesinin artırılması için gerekli düzenlemeler yapılmalıdır. Mobilya endüstrisinin yoğunlaştığı bölgelerde 'Modern Tasarım' eğitimi veren okulların açılması, sektörde üniversite ve sanayi işbirliğini sağlayacak mekanizmaların oluşması adına atılabilecek önemli bir adımdır. Ayrıca, hizmet içi eğitim programları ile gelişen teknolojiyi takip etme konuları gündemde yer almalıdır. İşletmelerde, profesyonel yönetici ve kalifiye iş gücü oranı düşüktür. Tasarım, üretim ve işletme konularında uzman kişiler çalıştırılmasına öncelik verilmeli ve istihdam teşviği sağlanma1ıdır. Türkiye'de mobilya endüstrisi büyük ölçüde iç pazara yönelik olduğundan, sektör firmaları dış piyasalar hakkında yeterli deneyim ve bilgiye sahip değildir. Geleneksel işletme yöntemleri ile çalışan işletmeler, uluslararası pazarlara açılmaktan ve dış piyasayla rekabet 
etmekten kaygı duyduklarından gelişme gösterememektedirler. Bunun önlenmesi amacıyla, dış pazar ile ilgili doğru bilgiye ulaşmak için yapılan araştırmalar desteklenmeli ve dış pazarı takip etmek için sergi ve fuarlara katılım sağlanmalıdır. Türkiye'nin dünya pazarındaki payını artırmak için sektörün ve ürünlerinin tanıtılmasına yönelik faaliyetler yapılmalı ve sektörün gerçek potansiyeli ihracata yansıtılmalıdır. İhracatta sağlanan sürecin gelişerek devam ettirilebilmesi için, firmaların yatırım ve ihracat teşviklerinden yararlanmaları sağlanmalı ve üretim/ ihracat kapasiteleri artırılmalıdır.

Mobilya sektöründe, pazarlama ve iletişim konusunda eksiklikler bulunmaktadır. Pazarlama faaliyetleri dış piyasada yetersiz kalmaktadır. Bu durum da üreticilerin rekabet şansını azaltmaktadır. Türkiye'de pazarlama organizasyonu, tüketicinin korunması, pazarlama ahlakı ve teknik koşulların saptanması gibi konular yeterli düzeyde gelişmemiştir. Bu maksatla eğitim ve bilgilendirme çalışmalarının akademik düzeyde uzman kişilerle yapılması yararlı olacaktır.

Türkiye mobilya sektörünün genellikle küçük ölçekli firmalardan oluşması ve zanaat geleneğini devam ettirmesi, fark yaratan bir üstünlük olarak değerlendirilebilir. Bu nedenle, zanaatkârların bilgi ve tecrübelerini gelecek kuşaklara aktarmaları sağlanmalıdır. Bununla birlikte, seri üretim ve otomasyon teknolojilerine de önem verilmelidir. Seri üretim yapan firmaların belli konularda uzmanlaşmaları sağlanmalı ve yeni üretim teknolojileri kullanmaları teşvik edilmelidir. Kalifiye iş gücü oluşumu bakımından meslek okullarına görev ve sorumluluklar verilmelidir. Ayrıca, üretim teknolojilerinin geliştirilmesi için sanayi kuruluşları tarafından maliyet düşürücü ve kalite yükseltici yeni tekniklerin uygulanması, yeni teknolojilerin geliştirilmesi veya yeni teknolojilerin ülke koşullarına uyarlanması gerekmektedir.

Sektörde ulaşım ağırlıklı olarak karayolu ile yapılmaktadır. Ancak mobilya ulaşım maliyetinden pekçok ürüne kıyasla daha çok etkilenmektedir. $\mathrm{Bu}$ sebeple alternatif taşıma yöntemlerinin araştırılması ve gerekirse mobilya sektörüne ayrıcalık tanınarak ihracata destek verilmesi sağlanmalıdır. Özen gösterilmeden yapılan nakliye ve aktarma 
işleri mobilyalarda hasara sebep olabilmektedir. Bu olumsuzluğu giderecek iyi organize edilmiş bir dağıtım sistemine ihtiyaç duyulmakla beraber nakliyatçıların da mobilya nakliyatında hassasiyet kazanmaları için eğitim aşamalarından geçmeleri gerekmektedir. Satın alınan mobilyanın alıcıya sağlam ve eksiksiz ulaşabilmesi için kullanılan kolileme sistemi, markalaşmanın gerektirdiği ürün paketi tasarımı ve sağlam ambalajlamanın yapılması sektörün rekabeti ve güvenilirliği için büyük bir önem taşımaktadır. Bu sebeple mobilyanın kullanıcıyı memnun edecek şekilde ulaştırılması için gerekli yöntemler kapsamlı bir şekilde izlenmelidir.

\section{Sonuçlar}

Endüstri Devrimi ile toplum yaşamındaki değişimler hız kazanmış ve büyük gelişmeler oluşmuştur. Yoğun nüfus ve konut artışı ile meydana gelen hızlı kentleşme sonucu geleneksel yaşam tarzı geride bırakılmış ve yerini modern yaşam almıştır. Mobilya, 21. yüzyılda günlük yaşamın her alanında yer edinmiştir. Toplumun refahını sağlayan, sosyal ve kültürel gereksinimlere hizmette bulunan, insan yaşam kalitesini etkileyen mobilya, insan yaşamı üzerinde en çok etkili olan ürün çeşitlerinden biridir. Kentsel dönüşüm projeleri, nüfus artışı, yükselen hayat standardı ve sektörün ihracat değerinin artması ile mobilyaya olan talep gün geçtikçe artmakta ve bu da doğrudan mobilya sektörüne etki etmektedir.

Türkiye'de mobilya tasarımı ve sektörünün sağlıklı bir çizgiye oturması ve uluslararası platformda yer edinebilmesi için gerekli adımlar atılmalıdır. Bu anlamda, standartlara uygunluk, iş gücü, tüketici talepleri, teknolojik yeniliklerin dikkate alınması küresel dünyayla rekabet edebilme seviyesine gelinmesini sağlayacaktır. Kendi kültürünü okuyup yorumlayabilmek, geçmişten gelen kültürü geleceğe yansıtabilmek özgün tasarımların oluşması için önemlidir. Günümüzde az sayıda tasarımcı uluslararası platformda Türk tasarımı adına ürünler verebilmektedir. Yeni fikirlerin ortaya çıkarılması adına, 
bireysel tasarım yapan tasarımcılara destek verilmesi tasarlanan ürünlerin dünyanın pek çok yerinde talep görmesine ve ürünlerin takip edilerek tercih edilmesine imkan taniyacaktır.

Türkiye'de mobilya imalat sektörünün büyük bir bölümü $\mathrm{KO}$ BI'lerden (Küçük ve Orta Ölçekli İşletme) oluşmaktadır. Sektörün temel sorunu, sermaye yetersizliği ve kredi maliyetinin yüksek olmasıdır. İşletmeler ticari bankalardan uygun koşullarda kredi temininde zorlandıkları için sermaye sıkıntısı çekmektedirler. Türkiye'de KOBİ'lere kaynak sağlayan finans kuruluşları tarafından kredi miktarının artırılması, sektörün önünü açarak yatırımcıların sorunsuz ilerlemesini sağlayacaktır. Küçük ve orta ölçekli sanayi geliştirme ve destekleme fonu kaynakları artırılmalıdır. KOBİ'lerin ortak alım ve satım şirketleri kurmaları, ortak hareket etmeleri ve işbirliğine girmeleri teşvik edilmelidir. Şehir içlerinde düzensiz, dağınık ve uygun olmayan mekanlarda imalat yapan firmalar bulunmaktadır. $\mathrm{Bu}$ da onların sıkıntılı üretim yapmalarına sebep olmaktadır. Uygun fiziki şartların sağlanması için planlı proje ve altyapısı tamamlanmış küçük sanayi siteleri ve organize sanayi bölgeleri oluşturulması sektörün gelişimini sağlayacaktır.

Türkiye'nin kendi markalarıyla dış pazara girmesi, rekabet gücünü artırması ve kalitesini yükseltmesi için kısa, orta ve uzun vadedeki üretim stratejilerini oluşturmas1 gerekmektedir. Bu nedenle, ürün tasarımının ilk sürecinden, ürünün geri dönüşüm aşamasına kadar etkili olabilecek bir tasarım oluşturmak adına tüm analiz ve sentezlerin iyi yapılması gerekmektedir.

\section{Kaynaklar}

[1] Terece, Z., 1950 Sonrası Türkiye'de Modern Mobilya Tasarım ve Üretimi, Yüksek Lisans Tezi, Haliç Üniversitesi, Fen Bilimleri Enstitüsü, (2017).

[2] Guggenbühl, P., Wohnen Einst and Jetz Möbel Entwurf Fertigung Vertriev Holzwirtscheaftilcheets, Yn.Nr.12, Stuttgart, (1962).

[3] Devlet Planlama Teşkilatı, Dokuzuncu Kalkınma Planı (2007-2013), Ağaç Ürünleri ve Mobilya Sanayii Özel İhtisas Komisyonu Raporu, (2006). 
[4] T.C. Kalkınma Bakanlı̆̆ı, Mobilya Çalışma Grubu Raporu, Ankara, (2015).

[5] World Furniture Outlook 2019, URL: https://furnitureandfurnishing.com/world-furniture-outlook-2019/, (Erişim Tarihi:10.03.2020).

[6] Orta Anadolu İhracatçı Birlikleri, Mobilya Sektör Raporu 2014, Ankara, (2014).

[7] Küçükerman, Ö., Sanayi-i Nefise Mektebi’nden Endüstri Tasarımına Mobilya, Orta Anadolu İhracatçı Birlikleri, Ankara, (2015).

[8] Orta Anadolu İhracatçı Birlikleri, Mobilya Sektör Raporu 2016, Ankara, (2016).

[9] Mobilya İhracatı İlk İki Ayda 578 Milyon Dolara Yükseldi, URL: https:// www.milliyet.com.tr/ekonomi/mobilya-ihracati-ilk-iki-ayda-578-milyon-dolara-yukseldi-6161641, (Erişim Tarihi: 10.03.2020).

[10] Türkiye Odalar ve Borsalar Birliği, Türkiye Mobilya Ürünleri Meclisi Sektör Raporu (2017).

[11] Nergiz, F., Minimalist Mekanların Tasarım Özellikleri ve Görsel Niteliklerinin Mimarlığın Bazı Temel Öğeleri Aracılığıyla Konut Tipolojisi Kapsamında İncelenmesi, Yüksek Lisans Tezi, Yıldız Teknik Üniversitesi, Fen Bilimleri Enstitüsü, (2005). 